\title{
EL MUSEO DE LOS VISITANTES
}

\author{
Silvia Alderoqui'
}

\section{RESUMEN:}

Hoy es imprescindible pensar nuevos modos para integrar a las colecciones y exposiciones con los públicos. Hay que pasar el tema de los visitantes de los bordes y márgenes al centro. Los museos no deben renunciar a su responsabilidad como instituciones culturales pero es necesario que coexistan diversidades de voces, ya que cuando esto sucede en el marco de una exposición se produce el enriquecimiento de ambos, museos y públicos.

\section{PALABRAS CLAVE:}

Visitantes; participación; rol social del museo; educación; cultura

\begin{abstract}
:
Today is essential to think new ways to integrate the collections and exhibitions for the public. We need to move the topic of visitors to the edges and margins to the center. Museums should not abdicate its responsibility as cultural institutions but need to coexist diversity of voices, because when this happens in the context of an exhibition enrichment of both museums and public occurs.
\end{abstract}

\section{KEYWORDS:}

Visitors, participation, museum's social role, education, culture

I Silvia Alderoqui, Licenciada en Ciencias de la Educación. Directora Museo de las Escuelas, Buenos Aires, Argentina.silvia.alderoqui@yahoo.com.ar 


\section{A modo de introducción}

En abril de 2012, se inauguró el Museo de la Inocencia en la ciudad de Estambul. Según cuenta el cronista español Juan Cruz Ruiz, el autor Orham Pamuk' había imaginado el museo antes de la novela homónima. En sus salas están los objetos narrados, recolectados de mercados viejos, amigos y parientes. El museo es la reconstrucción de su deseo de recordar y evoca una época particular de Estambul.

Por medio de la novela Museo de la Inocencia, Pamuk hace realidad su deseo de museo y de algún modo se da cita con el concepto de museo imaginario de Malraux. En 1947, André Malraux había expuesto la idea premonitoria del museo imaginario realizado a partir de la subjetividad de quien lo crea y sin límites de tiempo ni espacio. En el museo imaginario no hay más discurso expositivo que el gusto del que imagina las obras de su museo ideal $y$, al modo de un álbum de fotografías, crea su propio museo de acuerdo con su sensibilidad.

Orham Pamuk lleva a cabo la operación sugerida por Malraux aunque sin su carácter portátil. El museo de Pamuk es un lugar donde el imaginario del escritor se hizo sensible también en el espacio físico. Como si Pamuk hubiera tenido la necesidad de la concreción de su imaginario en el contacto directo con las obras y objetos.

A partir y simultáneamente con la creación de su museo, Pamuk elabora un modesto manifiesto que inicia de este modo:

Amo los museos, y no soy el único que encuentra que cada día que pasa nos hacen más felices. Me tomo los museos muy en serio, $y$ eso a veces me conduce a pensamientos airados y enérgicos, pero no soy una persona que pueda hablar con ira de ellos. Cuando yo era niño en Estambul había muy pocos. La mayoría eran simplemente monumentos históricos que se habían preservado o, lo que es bastante más raro fuera del mundo occidental, eran lugares con un aire como de oficina del gobierno. Más adelante, los pequeños museos de las callejuelas de las ciudades europeas me llevaron a darme cuenta de que los museos (igual que las novelas) también pueden hablar de los individuos. 2

A partir de esta introducción ordena sus pensamientos para darnos a conocer sus ideas vinculadas con las historias que deberían ser relatadas en los museos. Según Pamuk, "las historias de los individuos son mucho más compatibles con la expresión de las profundidades de nuestra humanidad" que las narraciones históricas de la sociedad, es decir, los museos deberían ser como novelas acerca de las historias cotidianas y ordinarias de los individuos, que son más ricas, más humanas y mucho más gozosas que las historias de las culturas colosales. Para Pamuk el desafío de los museos es poder contar en forma tan brillante, profunda y potente como se cuentan las "grandes historias" nacionales, las historias de los seres humanos individuales que viven en esos países, revelando así su humanidad. Según el autor este sería uno de los modos en que miles

I El escritor turco Orham Pamuk obtuvo el Premio Nobel de Literatura en 2006.

2 Extraído de Modesto Manifiesto por los museos: http://cultura.elpais.com/cultu$\mathrm{ra} / 20$ I2/04/27/actualidad//335549833_0209/6.html 
de personas que tienen temor de entrar a los museos se animarían a atravesar sus umbrales.

\section{La participación de los visitantes}

El énfasis resaltado por Pamuk en las historias cotidianas de los individuos y el territorio propio, en contraposición con los museos tradicionales y los grandes relatos resuena con los conceptos de la museología latinoamericana de los años 1970 y la nueva museología de los años 1980. Por un lado, en la ya memorable "Mesa de Santiago" de 1972 se había introducido la "novedad" de que los visitantes eran tan importantes como los objetos y por otro, en la Declaración de Quebec de 1984, se postulaba que frente al dogma de la conservación era necesario proclamar la primacía de la participación y el diálogo enriquecedor entre los museos y sus comunidades.

Hay también un antecedente poco difundido que es un seminario ${ }^{3}$ organizado en 1967, por el director del Museo de las Ciudad de Nueva York, Ralph Miller, quien invitó al especialista canadiense en comunicación, Marshall McLuhan y a su asociado Harley Parker, a reflexionar acerca de comunicación museal. McLuhan y Parker manifestaron, acerca de la atmósfera museal, sus sentimientos de claustrofobia y aburrimiento, y la ausencia de comunicación en el interior de los museos. Pero por sobre todo, denunciaron la ausencia de interés por parte de los museos de llevar a cabo investigaciones para poder "comunicar realmente las informaciones a los visitantes". Defendían la idea de que los museos además de personas que se ocuparan de los objetos debían tener personal que se ocupara de los visitantes y sus "reacciones", para poder diseñar mejor las exposiciones. Decían entonces los especialistas:

Harley Parker: ... Un conservador se pasará meses consagrado a buscar el eslabón faltante de su colección. En lugar de consagrar su tiempo a explotar el material que está a su disposición para decir alguna cosa, pasará su tiempo buscando...

Mc Luhan: Sería una maravillosa ocasión para sugerir al público de aportar ese eslabón, indicándole cuando hay un elemento faltante de la colección. El público sentiría placer de poder proporcionar ese elemento. Es todo el encanto de las historias policiales. Usted elimina sabiamente todos los lazos y conexiones entre la prueba y los elementos de la historia en vistas de provocar la participación del público... (McLuhan, 2008: 38-39)

Las discusiones fueron apasionadas y desestabilizantes para la mayoría de los directores y conservadores de museo presentes en el seminario. McLuhan y Parker plantearon ideas radicales para los museos tradicionales, concebidos con formato enciclopédico: abrir los museos de noche, sacar algunos artefactos de sus vitrinas y crear vitrinas envolventes de los visitantes; dispositivos museográficos para tocar, reproducciones a escala, los espacios de inmersión, la modulación de la iluminación para forzar la implicación del visitante, los visitantes como co-productores y co-creadores, salas para niños, el diseño de experiencias significativas en términos personales e identitarios, el sentido del

3 Seminario desarrollado en el Museo de la Ciudad de Nueva York los días 9 y 10 de octubre de 1967, publicado originalmente bajo el título Exploration of the ways, means and values of...Museum Comunication with the wiewing public, New York, Museum of the City of New York, 1969. 
humor, la recreación de ambientes sensoriales para montar los artefactos de las colecciones que pudieran revelar cómo habían sido producidos y utilizados, salas no verbales, sin rótulos, el despliegue de la imaginación, de los múltiples lenguajes, espacios táctiles, olfativos y acústicos, exposiciones no lineales,

Estas ideas sonaron entonces, francamente extremistas.

Nos preguntamos, casi cincuenta años más tarde, por qué ha sido tan difícil que estos postulados dieran origen a la generalización de prácticas de comunicación museal innovadoras que incluyeran a los visitantes y las comunidades en roles más activos que los que aún podemos observar en la actualidad.

Según Ignacio Díaz Balerdi (2002) la nueva museología no fue recibida con simpatía por la museología tradicional por ser considerada como una especie de anti-museología que concebía el museo como una herramienta al servicio de la comunidad y no como un fin en sí mismo.A pesar de las resistencias dice Balerdi, hay una serie de cambios en el mundo de los museos inimaginables sin el concurso de la nueva museología.

Estos cambios impactaron, entre otras cosas, en la necesidad de nombrar los museos por medio del recurso de la adjetivación: museo integrado, relacional, comunitario, nuevo, local, total, crítico, creativo, social; los prefijos como eco; los complementos directos como de sociedad, de vecindad, de barrio, etc. Todos intentos de rescatar la institución de las "garras del pasado", para dejar atrás su exclusiva variable temporal y objetual y para arraigarla en el territorio, en las ideas del presente, en los sujetos, en la comunidad. El reconocimiento de la relación recíproca entre la sociedad y el museo exigía un uso creativo de las colecciones: dejar de ser exclusivamente un "tesoro que proteger" para convertirse en un recurso verdaderamente colectivo.

La construcción de una nueva imagen de los visitantes también tiene una genealogía vinculada con la genealogía de los museos y también con los estudios de público. En un ejercicio de deconstrucción y reconstrucción de la concepción de lo que es una audiencia de museos (Illeris, 2006) establece una genealogía a partir de tres imágenes: el ojo ilustrado, el ojo conocedor y el ojo deseante, pasando de concebir al público general indiferenciado hasta analizar audiencias diversificadas.

-El ojo ilustrado: Al principio (SXIX) los visitantes eran considerados como público general compuesto de "sujetos educados", personas racionales que podían ser instruidas a través de la organización didáctica de una exposición y el personal del museo. El "ojo ilustrado" miraba los objetos desde una distancia controlada. Los que no pertenecían a esta clase eran los que no sabían comportarse en un museo, los que no tenían conciencia de lo que era ser un visitante de museo.

-El ojo conocedor. Se ubica en las primeras décadas del siglo XX y está relacionado con los estudios de la psicología moderna. El visitante era el sujeto educado autodisciplinado, con conciencia de sus propias habilidades, aptitudes y necesidades, el que tenía las facultades naturales de la "sensibilidad y el gusto". Los que no pertenecían a esta clase eran los que no tenían "gusto ni distinción".

-El ojo deseante. Los visitantes son responsables de su aprendizaje y participan activamente, incluyendo sus necesidades, habilidades y limitaciones. El ojo deseante desea comprometerse y tiene un deseo personal de compartir 
su experiencia en situaciones educativas. Los educadores se consideran facilitadores de la participación y esperan poder involucrarlos no solo en temáticas vinculadas con el museo sino en cuestiones relacionadas con la vida personal. Los museos son centros de aprendizajes diversos. Los "otros" son más difíciles de encuadrar porque es un enfoque más inclusivo.

Sin embargo, a pesar de esta tipología que podría hacernos suponer que en la actualidad todos los museos son visitados por muchos "ojos deseantes", hay que tener en cuenta que ser parte de una audiencia/público de museo es una construcción social. La igualdad del derecho a los bienes culturales comunes no se corresponde con las igualdades de hecho. Hay una gran parte de la población que no se siente autorizada y aceptada para atravesar los umbrales de los museos y otros que no se sienten representados por lo que se exhibe en sus salas.

Como dice Jocelyn Dodd (2002) no se trata de pensar en lo que les falta a nuestros visitantes (modelo del déficit) sino de lo que nos falta a nosotros para ser interesantes para ellos. Estas cuestiones deben ser estudiadas desde el núcleo ético de las prácticas de gobierno de cada museo ya que en muchos casos los mismos museos son la causa de estas dificultades. No se trata solo del diseño de programas educativos y culturales destinados a variedad de públicos -adultos y niños; videntes y no videntes, grupos familiares y escolares; adultos mayores; etc.- sino de convertir a los museos en lugares para juntarse con otros y creer sinceramente que la centralidad de los museos es la relación entre los visitantes y los objetos. Se trata de concebir al museo como un espacio relacional compuesto por una densa red de relaciones internas - entre diferentes funciones y especializaciones - y externos - entre el museo, el territorio, las partes interesadas y la sociedad en sentido amplio (Bodo, 2003).

Es un proceso de movilidad y movilización, de fuerte participación, de alto compromiso.

Ya entrados en el siglo XXI, las narrativas de los visitantes tienen un lugar protagónico en las prácticas de muchos museos innovadores y desde el marco de la denominada museología crítica que concibe a los museos como espacios de diálogo, conflicto, tradición, contradicción, resistencia, colisiones, fusiones y transformación social. Carla Padró y Fernando Hernández (200I) señalan que la museología crítica implica una reorganización radical en la cultura del museo. Desde esta perspectiva, las estructuras organizativas, las fases expositivas y las culturas profesionales responden a un modelo dialógico y narrativo en el cual las narrativas de los visitantes son tan protagonistas como los objetos. Los procesos de comisión, curaduría, gestión y educación son reinventados a partir de estructuras más flexibles, de trabajo en equipo y de proyectos polivocales (Padró y Hernández, 200I).

En el enfoque de la museología crítica, los educadores ocupan un lugar central no sólo en la organización de actividades y propuestas educativas pensadas a partir de exhibiciones ya existentes, sino, cada vez, más en las etapas de diseño y evaluación de exposiciones y proyectos museográficos. Este cambio contribuye a la reducción del conflicto existente entre conservación, educación y comunicación.

Sin embargo, este lugar de "hacedores" a ser ocupado por los visitantes en los museos del siglo XXI no está aún reconocido en las definiciones oficiales de 
museo. Según Jennifer Harris (2007: 61-69), miembro del Comité Internacional para la Museología (ICOFOM), sería más democrático considerar a los públicos como parte integrante del trabajo de los museos en el sentido de escucharlos y aprender de ellos en forma evidente para todos favoreciendo la participación, comunicación y el intercambio entre diversos grupos de personas. Algunas experiencias demuestran que es posible mantener la posición de lugar experto tanto como de líder cultural en la comunidad y comprenden el rol social del museo tanto como una acción en dirección a los públicos que no los frecuentan habitualmente, como acerca de los visitantes concebidos como actores principales (Caillet, 201 I: I5).

El cambio de paradigma del museo centrado en la colección al centrado en las personas, es sutil pero perceptible. Plantear la participación de los visitantes en los museos reclama abordar el concepto de comunidad en toda su complejidad (Alderoqui, Pedersoli, 200I: 17). Los especialistas del Manchester Museum ${ }^{4}$ definen a la comunidad como cualquier grupo de personas que optan por identificarse entre sí y como un concepto en un constante estado de flujo con alcances diversos: la zona geográfica, los intereses profesionales, las condiciones económicas, las circunstancias culturales, las necesidades valores y roles compartidos; además cada persona puede pertenecer a varias comunidades a la vez. (Kershaw, 20I3:12).

Teniendo esto en cuenta, se trata de poner en el centro de las preocupaciones y las ocupaciones del museo las necesidades de la comunidad en un sentido amplio, junto con las experiencias que generan los objetos de una colección, en todos los participantes: visitantes y profesionales del museo. Para llevar a cabo este cambio de paradigma, Nina Simon (2009) establece que se requiere un sentimiento de confianza en el potencial de los proyectos participativos que debe ser asumido por todos los que trabajan en el museo.

Como vimos anteriormente las cuestiones de participación y representación en los museos apenas conmueven los bordes institucionales. Como dice Georgina DeCarli para abordar la participación de la comunidad son necesarios "grandes cambios" en las instituciones museológicas, sobre todo en la preservación, investigación y comunicación del patrimonio, que es donde radican los desacuerdos más fuertes entre la museología tradicional y la participativa (DeCarli, 2004: 25)

La participación de los visitantes en el museo, es fácil de imaginar y difícil de sostener. Una vez puesta a rodar hay que ser fiel a ella y esto no es sencillo. En el corazón de la propuesta participativa reaparece la complejidad vinculada con el hecho de compartir el poder del conocimiento acerca del patrimonio lo que genera ciertos temores asociados con la confiabilidad de los contenidos, el saber experto menoscabado y la pérdida de autoridad. Pero, si reducimos la cuestión de la participación a cuestiones de control y poder, nos perdemos los beneficios de trabajar en conjunto con la comunidad.

Seguramente habrá que enfrentar los conflictos que se susciten cuando se instalen oportunidades de aprendizaje compartido y colaboración entre los

4 Programa de trabajo con la comunidad del Manchester Museum http://www.museum.manchester.ac.uk/ community/communityengagement/. 
museos y las instancias comunitarias. Sin embargo es importante reafirmar que la curaduría de la participación no es la abdicación de las responsabilidades curatoriales, educativas y de diseño por parte del museo. Más bien es un tipo de responsabilidad diferente que requiere aún mayores niveles de conocimiento. La co-creación tiene más beneficios que problemas y como beneficio más importante se trata de trabajar en conjunto con nuestros públicos para crear algo nuevo.

¿Cómo enfrentar y trabajar con los "conflictos" que se suscitan cuando se crean oportunidades de aprendizaje compartido y colaboración entre los servicios de los museos y diversas instancias comunitarias?

Con respecto a estas cuestiones hay interesantes reflexiones basadas en la experiencia de las especialistas Bernardette Lynch y Sally MacDonald con los museos de las ciudades de Glasgow, Newcastle y Londres. El proyecto se llama Objetos en conflicto ${ }^{5}$. Tal como señalan las investigadoras, más allá de las buenas intenciones de los museos, en los proyectos comunitarios se suele deslizar "la autoridad coercitiva del museo" que silencia cualquier oposición o resistencia a la forma tradicional de interpretación de la colección. Este tipo de experiencias lleva a la desilusión de los participantes y pueden fracturar la relación de un museo con su comunidad.

Si un museo quiere convertirse en una institución participativa en el corazón de la sociedad civil, es necesario trabajar y capacitarse en el trabajo con y a través del "conflicto". Solo desarrollando una práctica reflexiva conjunta se puede evitar que las sutilezas de las relaciones de poder lleguen a falsos consensos. Esto significa que los profesionales de los museos necesitan que sus pares comunitarios los ayuden a enfrentar los "conflictos" para desarrollar en forma conjunta diálogos democráticos en los museos y, por sobre todas las cosas, y esto es válido para todos los participantes, desarrollar nuevas habilidades como ciudadanos.

Estos son los comentarios del director del museo, Nick Merriman, a propósito de un proceso de co-creación de contenidos en una exposición sobre racismo y prejuicios raciales en el museo de la Universidad de Manchester:

...fue lo más cerca que estuvimos de un proceso de co-creación auténtica, pero para ser sinceros, fue más difícil de lo que pensábamos. Nos sorprendimos con el apasionamiento de las personas...es difícil manejar correctamente las expectativas que se crean... ${ }^{6}$ (Lynch y Alberti, 2010: 13-35)

Ahora veamos las reflexiones de la directora de la Brooklyn Historical Society, Deborah Schwartz, en una entrevista titulada La comunidad como curadora:

...Yo creo que [compartir autoridad con la comunidad] es muy interesante, seductor, inteligente, un poco impredecible en el buen sentido de la palabra...Presto mucha atención a todas las lecciones que se pueden aprender de cada uno de estos intentos que hacemos. Pienso que nos estamos preguntado todo el tiempo cómo queremos posicionarnos en un mundo en el cual somos buscados como poseedores de cierta clase de autoridad. Estamos empujando los límites todo el tiempo, espero que siempre sigamos empujándolos, porque creo que esto nos da siempre

5 Museums, objects, participatory democracy and conflict http://objectsinconflict.wordpress.com/about/ the-proposal/

6 La traducción es propia. 
resultados increíbles... ...Porque elegimos ceder nuestra autoridad hasta cierto punto, vivimos con una cierta incomodidad sabiendo que en algunos casos el proceso de crear exhibiciones compartidas con la comunidad será mejor que el producto. Esta es la parte más controversial de este asunto. Esta es la parte que hace que para alguna gente del mundo de los museos esto sea inaceptable. ${ }^{7}$ (Swartz y Adair, 2011: 112 a 123)

Con respecto a la co-creación de contenidos en formatos virtuales Mariana Salgado (2013:17) formula una serie de afirmaciones muy interesantes:

- El contenido creado por la comunidad surge como resultado de una empresa colaborativa que le da forma a la práctica de la participación.

- La variedad de perspectivas sirve para desarticular la noción de que existe "una sola verdad" sobre el contenido de una exposición.

- El contenido creado por la comunidad puede ayudar a que el museo "cuente una historia más precisa y completa" para que los visitantes de todos los grupos culturales tengan la posibilidad de decir:"Esta es mi historia”.

- El diseño orientado a prácticas participativas debe contemplar diferentes voces y discursos con el fin de intentar crear un mosaico más inclusivo en el cual pueda escucharse cada voz.

-El contenido creado por la comunidad es útil para diversos actores solo cuando se incluye a muchos de ellos en el proceso de diseño.

La exigencia mayor de los proyectos de participación y co-creación con la comunidad es su documentación y el mayor problema su generalización y cristalización en el tiempo.

Cuando se trabaja con la comunidad se requiere un trabajo de investigación, archivo, clasificación, análisis del discurso y edición de voces comunitarias que transforme impresiones, presunciones, sensaciones, pareceres, imágenes, borradores y papeles sueltos en hipótesis, premisas, grandes ideas, narrativas, conceptos e imaginarios productivos. En todos los casos hay que sostener un liderazgo capaz de generar confianza frente a los diferentes puntos de vista, tanto hacia los participantes de la comunidad como hacia los diferentes profesionales del museo.

Si un museo adopta una estrategia de participación comunitaria es necesario asegurar que todo lo que se haga esté impulsado por la colección y centrado en los usuarios reales y potenciales. Pero no alcanza con hacer participar a los visitantes y a la comunidad en actividades y propuestas diversas, además hay que trabajar para pasar de la participación a su representación. Esto quiere decir que este compromiso tiene que ser visible y evidente en cada exposición, de modo tal que los conocimientos, voces y experiencias de los visitantes, además de ser consultados, se conviertan en propuestas expositivas novedosas, se adivinen en la reescritura de los rótulos, reaparezcan en la interpretación de la colección, se incluyan en la museografía, la política y documentación del museo, etcétera.

7 La traducción es propia. 


\section{La curaduría de los visitantes}

En algunos museos se utiliza la denominación "curaduría de visitantes" para dar cuenta de la especificidad de la tarea de "ocuparse de los visitantes" como sugerían McLuhan y Parker a fines de 1960. De este modo se la pone en valor y se la considera como dijimos antes mucho más que una programación cultural y educativa de atención de públicos.

Solo cuando la comunidad, los visitantes, el público son tenidos en cuenta y no solo contados-, los museos, pueden empezar a conmoverse y transformarse.

Para dar ese paso que no es un simple juego de palabras sino una forma de ocupar el espacio museo con personas y no solo con cosas, hay que estar convencido de que lo que liga a los individuos es el poder común de la igualdad de las inteligencias como dice Rancière (2010:22) y que todos tenemos capacidades de traducción e interpretación que nos vuelven semejantes en la diversidad.

Todas las personas tenemos la capacidad de testimoniar, de organización de lazos de solidaridad, de capacidades de creación, aún en situaciones muy duras, desplegamos capacidades de resistencia y de protesta y ocupación de espacios con objetos, expresiones, músicas, raíces, recuerdos y fotografías que hacen parte de nuestra identidad. Creamos, interpretamos y atribuimos significado en función de nuestros conocimientos y del contexto social y cultural en el que nos desenvolvemos. Dado que los significados no son estáticos y tampoco intrínsecos a los objetos siempre puede haber algo para agregar, poner en valor, desmentir o modificar. En algunos casos esto derivará en la creación conjunta y generación activa de contenidos y construcción de los relatos de interpretación, lo que amplificará la experiencia de visita y la inclusión de nuevas ideas y nuevos públicos.

Desde esta perspectiva las exposiciones en los museos posibilitan realizar "trabajos de identidad". Un trabajo de identidad concebido como proceso a través del cual se construye, mantiene y adapta nuestro sentido de identidad personal, y persuadimos a otras personas a creer en esa identidad al mismo tiempo que accedemos al conocimiento de identidades diversas. Este tipo de experiencias suceden habitualmente por razones personales más que públicas y están fuertemente motivadas por las necesidades de formación y reforzamiento identitario. Disfrutamos de "encontrarnos" y de encontrar algo que nos "pertenezca" en los museos y también de sentir que la experiencia en el museo redundará en algún beneficio para nuestra vida (Volkert, 1996). Además los visitantes, con sus miradas y acciones también reconstruyen aquello que se presenta y representa. Participan de esta manera de la construcción social de los significados, tanto como el personal del museo.

La curaduría de los visitantes implica crear condiciones de apropiación de los bienes comunes para muchas personas más de las que ahora son parte de las audiencias de los museos. Es decir ofrecer experiencias de calidad para que diversos tipos de visitantes pongan en juego sus perspectivas, conocimientos, narrativas y emociones y reconozcan en las exposiciones algo propio: un objeto, un recuerdo, una pregunta, una búsqueda, una emoción de deleite o enojo, una pérdida o una alegría, la nostalgia y la imaginación. 
Hay que instalar relaciones de confianza y situaciones sociales de intercambio como dar la bienvenida, invitar, acoger, recibir, que demuestren que lo que dicen, piensan y opinan los visitantes nos transforma, nos importa y mucho. Los visitantes actúan observan, seleccionan, comparan, interpretan, participan. Si los invitamos se convierten en habitantes, socios y actores de la puesta en escena expositiva. Tenemos maravillosas oportunidades de conectar con ellos y capturar sus diálogos con el museo de modo que tanto ellos como nosotros salgamos enriquecidos.

Los profesionales de museo como "especialistas en visitantes" tienen que tener en cuenta los llamados Derechos de los visitantes (Rand, 200I: 7) en todas y cada una de las actividades y programas que llevan a cabo:

Comodidad: Incluye sanitarios y asientos para descansar bien señalizados y bien ubicados. Igualmente importante es el fácil acceso a los objetos de la exposición.

Orientación: Señales claras y visibles y una distribución de las salas bien planeada. Los visitantes saben a dónde tienen que ir, cómo llegar y que les espera allá.

Sentirse bienvenido: Empleados cordiales y dispuestos ayudan al visitante a sentirse cómodo.

Motivación: Si los visitantes se encuentran con obstáculos (objetos rotos, actividades que no llaman mucho su atención o textos de descripción demasiado largos o intimidatorios) se sienten frustrados, aburridos y confundidos.

El aspecto social: Los visitantes muchas veces van a los museos en grupos de familia y amigos y para encontrarse con otros. Quieren hablar con otras personas, interactuar y compartir experiencias. Así las exposiciones funcionan como lugar de encuentro.

Respeto: Los visitantes quieren ser respetados sin importar los intereses y conocimientos que tengan. No quieren ser ignorados, o tratados de manera despectiva o displicente, y no quieren sentirse ignorantes. Los textos tampoco deben transmitir esta sensación.

Comunicación: Los visitantes esperan de los textos, de los programas y de los docentes veracidad, sinceridad y mensajes precisos. Quieren plantear preguntas, a veces, incluso quieren escuchar o expresar opiniones discrepantes.

Aprendizaje: Los visitantes quieren aprender y experimentar algo nuevo, pero todos tienen su propia manera de aprender. Por eso es importante saber de qué manera aprenden y es importante adaptarse a sus intereses y conocimientos. Eso incluye la eliminación de factores que desvían o estorban el aprendizaje: muchedumbres, ruido o un aluvión de informaciones.

Posibilidades de selección y autodeterminación: Los visitantes necesitan una cierta autonomía: La libertad de elegir, de ejercer el control, de acercarse a las piezas expuestas que les interesan, quieren moverse libremente.

Reto y auto confianza: Los visitantes quieren tener una sensación de éxito. Una tarea demasiado fácil les aburre, mientras que una tarea demasiado difícil provoca el temor de no poder vencerla. Una oferta versátil de posibilidades puede cubrir un gran espectro de diferentes habilidades. 
Estimulación y restauración mental: Si los visitantes están en la exposición de manera muy concentrada, la disfrutan, se sienten cómodos, se divierten y se olvidan del tiempo, se van a sentir restaurados mentalmente después de su visita.

Hay múltiples opciones para conectar con los visitantes y capturar sus diálogos, estas "conversaciones provocadas" producen resultados de diversa índole, el museo se acerca a los conocimientos de la comunidad, expectativas e intereses sobre los temas en exposición, sus relatos, sus prejuicios e ideas previas. Se trata de crear circunstancias y experiencias por medio de puentes cognitivos y emocionales construidos entre los objetos en exhibición, entre los textos, a cada momento y entre las narrativas de las personas. Los contenidos culturales de la institución como el museo, combinados con las complejidades y recuerdos de cada visitante, pueden evocar profundamente sentimientos, iluminar cuestiones desconocidas y abrir puertas a experiencias no comprendidas con anterioridad.

Es preciso, pues, encarar un verdadero diseño de la participación para entusiasmar a los visitantes a participar, donde cada formato sea pensado en función de qué clase de participación solicitamos a nuestros visitantes y qué implica cada una de ellas para la institución. Cada propuesta de co-producción, colaboración, contribución o co-creación, exige un diseño específico: espacios íntimos, de transición o colectivos; consignas abiertas o cerradas; con o sin mediación; propuestas de corto y largo alcance; de alta o baja tecnología; etcétera.

Como curadores de visitantes podemos diseñar experiencias para que los visitantes encuentren significados personales con los objetos de la exhibición en sus propios términos y luego nos comenten sus elecciones y reflexiones. De este modo podemos observar si la atribución de sentido está vinculada con los rótulos, la información escrita, otros soportes interpretativos, la museografía, etc., y explorar otros modos y formatos para ofrecer dispositivos interpretativos que puedan favorecer que muchos visitantes más encuentren significados personales con la colección.

Como curadores de visitantes también podemos analizar la programación interpretativa del museo para elaborar nuevos relatos que permitan establecer lazos con temáticas concernientes a las grandes cuestiones humanas (sufrimiento, creencias, nacimiento, alimentación, refugio, generaciones, muerte, alegría, tristeza, etc.). Contar historias con detalles humanos. Una idea que resuena con los pensamientos de Pamuk con los que iniciamos esta comunicación.

En cuanto a la organización de las visitas, también hay posibilidades de innovar si nos centramos en la experiencia de nuestros visitantes y no solamente en los objetos de la colección. Es necesario conectar con los visitantes, contar historias con todo el cuerpo y la voz para crear imágenes en la mente de los visitantes acerca de la información a transmitir; enseñar a "perderse" en el museo, etc. Las visitas centradas en los visitantes se organizan alrededor de técnicas de narración, indagación e interpretación que varían en su utilización según los grupos sean de escolares, familias, público de fin de semana, grupos con necesidades específicas. Las técnicas no son mutuamente excluyentes sino complementos unas de otras. La narración puede proveer información para un proceso de indagación, mientras que la improvisación puede darle sentido a una historia (Thiele y Hatano, 200 I: 35). 


\section{A modo de cierre}

Aventurarse por los caminos de la centralidad de los visitantes en los museos requiere de analizar, profundizar y demostrar ciertos supuestos acerca de los beneficios y la democratización que se promueven por medio de estas prácticas.

Al mismo tiempo es necesario preguntarse acerca de los impactos de los resultados de la participación en otros grupos de visitantes, si se trabaja con mayor cantidad de visitantes o solo comunidades diferentes a las habituales, cómo se experimenta el contenido cuando está producido a partir de las voces de los visitantes y si las propuestas participativas aumentan el compromiso de los visitantes (Satwics y Morrisey, 20I I: 196 a 198).

La participación de los visitantes en los museos es zona de conflicto y ambigüedad acerca de cómo los visitantes se hacen parte del museo Es necesario seguir intentándolo, y probar una y otra vez cómo recorrer el laberinto, para encontrar la diversidad de caminos y salidas a pesar de las dificultades y aprendiendo de cada una de ellas.

Actualmente los profesionales con mayor contacto con la comunidad y con mayores posibilidades de convertirse en especialistas de los visitantes, son los educadores/facilitadores/guías de museo. Son quienes tienen las posibilidades de observar continuamente a los visitantes, aunque no siempre documenten esas observaciones. En este marco, pueden aportar elementos, intereses y criterios sobre las experiencias, interpretación, aprendizaje, imaginación y participación de los visitantes que influyan en el proceso de la toma de decisiones. El trabajo interdisciplinario podría dar excelentes frutos para que los visitantes sean y se sientan cada vez más parte de sus museos.

\section{Bibliografía}

ALDEROQUI, Silvia y Pedersoli, Constanza. La educación en los museos. De los objetos a los visitantes, Buenos Aires: Paidos, $201 \mathrm{I}$.

BODO, Simona (a cura di), II museo relazionale. Riflessioni ed esperienze europee, Torino: Edizioni della Fondazione Giovanni Agnellivia, 2003.

CAILLET, Élizabeth. “Le Rôle social du musée”. En Angèle Fourès, Delphine Grissot et Serge Lochot(dir), Le Rôle Social du musée.Agir ensemble et créer des solidarités, Les dossiers de l' OCIM, Université de Bourgogne, 201 I.

DECARLI, Georgina. Un Museo Sostenible. San José C.R.: Unesco, ILAM, 2004.

DÍAZ Balerdi, Ignacio “¿Qué fue de la nueva museología? El caso de Quebec”. En Artigrama, No 17: 493-516, 2002. Recuperado de:

\section{http://www.unizar.es/artigrama/pdf/I7/3varia//3.pdf}

DODD, Jocelyn. Interactivity and Social Inclusion, Research Centre for Museums and Galleries, University of Leicester, 2002. Recuperado de: http://media. vam.ac.uk/media/documents/legacy_documents/file_upload/576I_file.pdf

HARRIS, Jennifer "Commentaires sur la Déclaration de Calgary. La définition du musée". En Mairesse, F. y Desvallées, A. (dir) Vers un définition de musée? Paris: L'Harmattan, 2007.

ILLERIS, Helene. Museums and galleries as performative sites for lifelong learnings: constructions, deconstructions and reconstructions of audience positions in 
museum and gallery education, Museum and Society, 2006. Recuperado de:

http://www.virtualmuseums.dk/uploads/hi/2\%20Illeris.pdf

KERSHAW, Anne. "The promise and challenge of community involvment in museums”. En ICOM News 66, n I, marzo, 2013.

LYNCH, Bernardette T.. y Alberti, Sammuel J.M.M..."Legacies of prejudice: racism, co-production and radical trust in the museum". En Museum Management and Curatorship, Vol. 25, No. I, March 2010, I3-35.

MALRAUX, André. Las voces del silencio. Visión del arte, Buenos Aires: Emecé, 1956.

MCLUHAN, M, Parker, H. et Barzun, J. Le musée non lineaire, Lyon :Aléas, 2008.

PADRÓ, C.; y HERNÁNDEZ, F. “¿Cómo pueden los educadores y educadoras facilitar

políticas interpretativas más allá de la conservación del patrimonio, en I Congreso Ibérico de Educación Artística, Maia, Portugal, 2001. Recuperado de: http:// www.prof2000.pt/users/marca/profdartes/carlapadro.html

RANCIÈRE, Jacques. El espectador emancipado, 2010. Recuperado de:

http://www.politicas.unam.mx/razoncinica/sitepapimesep201 //sitio/Jacques Ranciere/texto.pdf

RAND, Judy. "The 227-Mile museum, or a visitor's bill of rights". En Curator. The Museum Journal. Walnut Creek, CA, Altamira Press, Vol.44, Number I, January, 7-I4, 200I.SALGADO, Mariana. Diseñando un museo abierto. Una exploración sobre la creación y el compartir de contenidos a través de piezas interactivas, Buenos Aires:Wolkowicz Editores, 2013.

SATWICS, Tom y MORRISEY, Kris. "Public Curation: From trend to research-based practice" En Letting Go?: Sharing Historical Authority in a User-Generated World, Bill Adair, Benjamin Filene, Laura Koloski, Filadelfia: Pew Center for Arts and Heritage, $20 \mathrm{II}$.

SWATRZ, Deborah y ADAIR, Bill. "Community as curator: a case study at the Brooklyn Historical Society”. En Letting Go?: Sharing Historical Authority in a User-Generated World, Bill Adair, Benjamin Filene, Laura Koloski. Filadelfia: Pew Center for Arts and Heritage, $201 \mathrm{I}$.

SIMON, Nina, The participatory museum, 2010. Recuperado de http://www.participatorymuseum.org/

THIELE, Scott y HATANO, Janet (editors). Partners in discovery: visitor centered tours. Transforming History school tours at the Oakland Museum of California. OMCA, $201 \mathrm{l}$.

VOLKERT, Jim. “Los museos en los albores del siglo XXl”, conferencia dictada en el Museo Etnográfico, Facultad de Filosofía y Letras UBA, Buenos Aires, 1996. Recuperado de: http://rch.retina.ar/hoy39/museo.htm 